\title{
Robotic Grinding Process of Turboprop Engine Compressor Blades with Active Selection of Contact Force
}

\author{
Andrzej BURGHARDT, Dariusz SZYBICKI, Piotr GIERLAK*, Krzysztof KURC, Magdalena MUSZYŃSKA
}

\begin{abstract}
The work presents a robotic system for grinding the blades of a turboprop engine compressor. The proprietary conceptual solution includes a data acquisition system based on a robotic 3D scanner, a neural decision system and a robot performing a grinding process with force control. The contact force of the tool to the blade was assumed as a variable and controlled process parameter. A neural network was used to generate the contact force on the basis of measured machining allowances on the blade. A virtual grid of several dozen regularly spaced points was placed on the surface of the blade. The neural network was learned the allowance-force dependence for the selected points, making it possible to select the proper contact force on the surface to be machined. The developed algorithm for the process of robotic grinding of the blades takes into account the necessity of ongoing quality control of the processing and the introduction of corrections in the process.
\end{abstract}

Keywords: blade grinding; force control; neural network; robotization

\section{INTRODUCTION}

The continuous development of sensory and executive systems enables the extension of the implementation of robotic systems into new areas of technology. Development work in the field of industrial robotization mainly concerns applications where a very large processrobot interaction is required. Such problems include the process of grinding blades, where there is a need to remove the variable machining allowance. The main driving force behind this type of work, in addition to minimizing human labour costs, is to improve safety conditions and increase the repeatability of the product.

The blades are elements of flow motors in which they are structurally mounted in the form of a palisade. Their shape provides the ability to convert the energy of a flowing fluid into mechanical energy. In reverse applications, the blades allow for the conversion of mechanical energy into the kinetic energy of a flowing medium (compressors). The aviation and energy industries are the main recipients of the blades currently produced [13]. There are a number of technologies for their production, from the most advanced, such as the process of casting blades by the monocrystalline method, to manufacturing them on CNC machines or additive manufacturing [4], up to the electrochemical method, which has been used for decades. Shaping blades as a result of electrochemical machining is economically justified; however, this technology is sensitive to a number of factors affecting the change of process parameters such as temperature, value of flowing current, gap width, etc. The uniqueness of blade design requires a manual individualized grinding process for each piece, and then finishing polishing.

In the field of blade geometry measurements, contact and contactless methods are used. Contact methods (Fig.1) involve the use of various types of automatic devices with measuring probes used to determine the dimensions of the blade at selected points. Examples of such devices are described in $[5,6]$. Sometimes robots with measuring probes [7] are also used, but this solution can only be used in the case of low requirements regarding accuracy, because the accuracy of robots is relatively small. Coordinate measuring machines (CMM) [8] are also used.
In non-contact methods laser devices [9] and various types of scanners [10] stationary mounted [11] or on robot arms [12] are used.

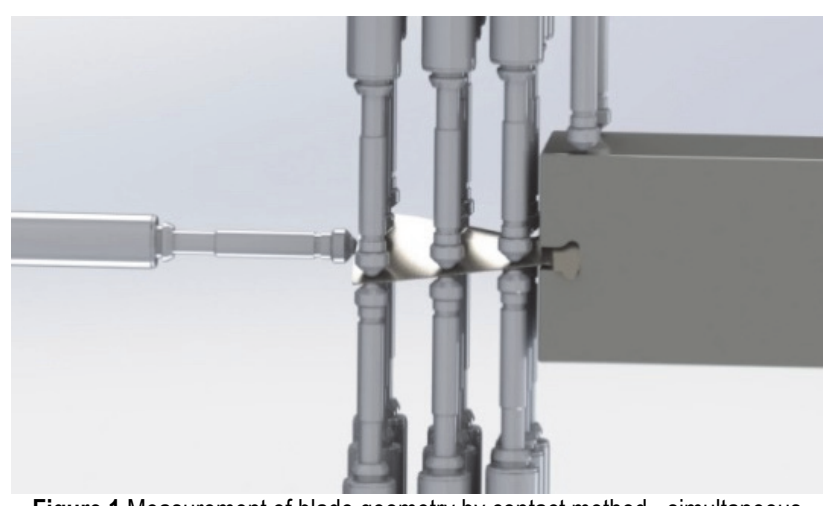

Figure 1 Measurement of blade geometry by contact method - simultaneous measurement of several points, including the position of the gripper

The advantage of contactless measurements (Fig. 2) is the ease of measurement, while measurements with contact devices can be troublesome for small sized blades. This is due to the fact that it is usually required to measure all points simultaneously with several probes with which the device is equipped. On the other hand, contact devices provide greater accuracy of measurement and are not sensitive to dust, the method of lighting the blades or reflections depending on surface roughness, which unfortunately are important in contactless measurements.

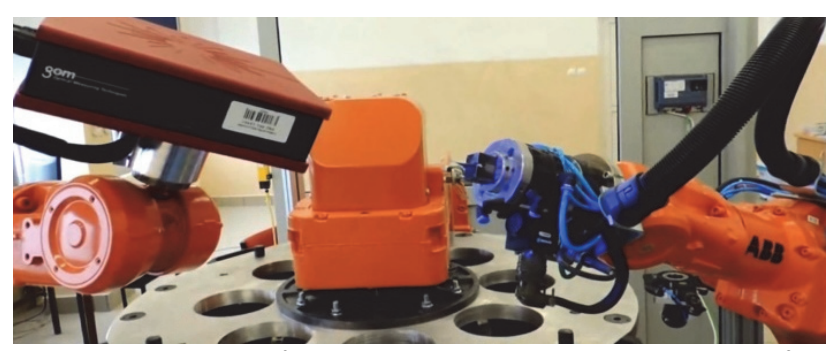

Figure 2 Measurement of blade geometry by contactless method - using a 3D scanner

In the field of blade robotics, not only the problems of the grinding or polishing process are considered, but also issues related to ensuring the machining accuracy [13]. The 
key issue here is the calibration of the robotic system [14], which affects the correct interaction of the machining tool with the blade. The grinding or polishing process is performed using belt grinders (Fig. 3) $[10,11]$ or rotary tools (Fig. 4).

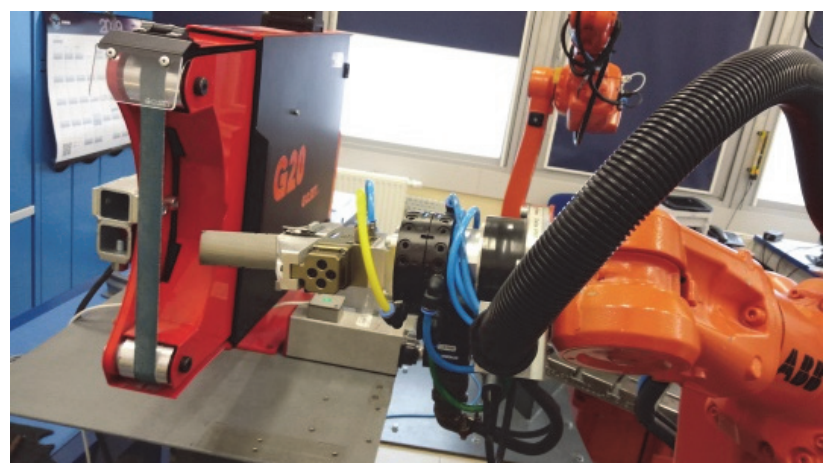

Figure 3 Robotic grinding process using belt grinder

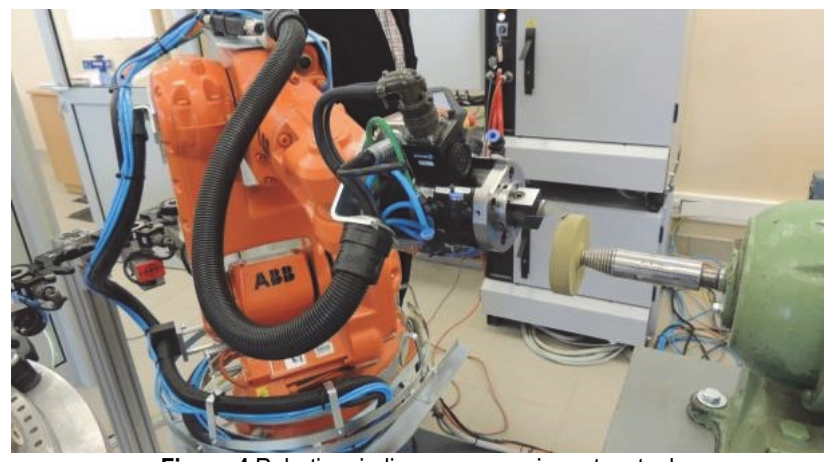

Figure 4 Robotic grinding process using rotary tool

The process of grinding or polishing blades essentially depends on three parameters. The first is the contact force of the tool to the blade, the second is the peripheral velocity of the cutting surface of the tool and the last is the feed velocity.

The contact force is applied in a passive or active way. In the passive method of applying the contact force, various types of flexible elements are used, such as springs or pneumatic systems that ensure the tool's contact force against the blade. It is possible to apply a variant in which the robot is equipped with a flexible tool and the blade is stationary, or the blade is in the robot gripper, which presses it against a tool which is affixed in a flexible manner. The force is not directly controlled here but depends on the deformation of the flexible element. The active method uses robots with the additional option of force control [15]. It is then possible to more precisely adjust the force, although this is a more expensive solution. Tools with the option of adjusting the contact force [16] are also used. The control of the peripheral velocity of the tool does not present difficulties, but it should be noted that this is a very important parameter on which the surface condition after machining depends. The result of an incorrectly selected velocity may be high roughness or overheating or scorching of the blade surface [17]. The feed velocity is the velocity of the tool movement relative to the blade or the blade relative to the tool - depending on which part is movable and which is fixed. As in the case of peripheral velocity, the feed velocity is a parameter whose control does not cause difficulties, but its selection is a very important aspect of the technology of blade production.
Too little feed causes the collection of too much material, and sometimes even overheating of the blade, and too much feed causes the surface to be unground. All of these parameters are selected experimentally depending, inter alia, on the shape and material of the blade and the type of machining tool. The results of research on the aspects of force distribution, tool wear, the amount of material removed occurring during robotic machining were included in the article [18].

In the field of modeling and optimization of the grinding process, there are a number of publications. They refer to a large extent to the study of the impact of process parameters on the properties of the machined surface and modeling the relationship between process parameters and the characteristics of this surface. In the work [19], the surface integrity of nickel-based superalloy Inconel 718, involving morphological structure, surface roughness, residual stress and structural domain size, was characterized. The optimal values of the belt grinding process parameters were determined, such as belt speed and grinding force, at which the minimum surface roughness and the desired value of compressive stress were obtained. In the paper [20], the grinding force was modeled with taking into account rotating tool speed, feed rate, and dynamic change of depth of cut. The developed model can be used to predict the dynamic grinding force and selection of grinding process conditions. In article [21] an overview of simulation methods describing the interaction of grinding process and grinding machine structure was presented. Main factors such as vibrations, deflections, or thermal deformations were taken into account. In turn, the article [22] presents an advanced probabilistic model of the grinding process considering the random arrangement of the grain vertices at the wheel active surface. Paper [23] presents an analytical model for precisely predicting grinding force, heat flux, heat partition ratio and temperature field during the grinding process. The work includes microscopic mechanism of interaction of the tool and the workpiece. Paper [24] presents analytical models of tangential and normal forces occurring in the robotic grinding process. The purpose of modeling was to use force models to improve the quality of the process. Often, artificial intelligence methods were used to model the grinding process [25-27].

A huge problem when trying to use the methods described in the publications is that the models are either in the form of black boxes or in the analytical form, in which the authors give coefficients for the particular case analyzed by them. Therefore, the results of the publication can be treated only as a guide to solving the problem of modeling the grinding process and it is difficult to reliably compare the new methods to the existing ones.

The aim of the work was to develop such a robotic grinding process that would take into account the individual geometric parameters of each blade. The most important grinding parameters are to be selected automatically on the basis of automated measurements that are part of the process.

In the following sections of this article, a detailed description of the issue of blade grinding and robotization of this process is presented, with particular emphasis on the elements of the test stand. A developed neural system for generating a desired tool pressure force depending on the 
parameters of the blade is presented. The novelty of the presented approach is taking into account the position of the machined area on the blade as a decision variable influencing the value of the desired pressure force of the tool. The use of this approach is justified by the variability of the curvature of the blade surface. The results of experimental research which confirm the correctness of the developed solution are also presented.

\section{DESCRIPTION OF THE PROBLEM}

The solution presented in the article concerns the blade grinding process based on the example of an aircraft motor blade. The process of grinding blades is monotonous, tedious, requiring manual skills, which means that it has great potential for robotization or automation [28]. In addition, this type of solution aims to significantly improve occupational safety and health in the plant and reduce the number of defective elements, improving the quality of the final product by eliminating from the technological process the human factor associated with stress, fatigue, mistakes etc. It was decided to apply the latest available solutions in the field of robotic machining. A variant was selected in which a blade placed in the robot gripper is machined using force control options. As a machining tool, a rotary abrasive tool was used. Contactless measurement of blade geometry is performed using a $3 \mathrm{D}$ scanner. To manage the machining process, a master system was used to generate the specified contact force of the blade on the tool. The system is based on the NN, which has learned the dependence between the contact force and the machining allowance at individual points of the blade.

Proper selection of the desired contact force of the tool on the blade is a complex issue. The literature review in Section 1 shows that there is no unified approach to this issue, and the specificity of the problem should be taken into account. In most cases presented in the literature, the grinding force can be generally expressed in the following form

$F_{\mathrm{n}}=f\left(Q, v_{\mathrm{r}}, v_{\mathrm{t}}, w, d, k, r, T\right)$

where $f$ - a non-linear function, $Q$ - removed allowance, $v_{\mathrm{r}}$ - feed velocity, $v_{\mathrm{t}}$ - velocity of the tool contact point, $w$ - degree of tool wear, $d$ - cutting depth, $k$ - stiffness of system, $r$ - surface roughness, $T$ - temperature. Typically, the impact of selected, only the most relevant parameters is analyzed and taken into account in the given case.

This paper presents the issue of machining a real blade whose shape is complex. The variable curvature of the blade makes the dependence on the contact force more complicated. The desired contact force also depends on the place where the tool is applied to the blade, i.e. the coordinates of the application point of the tool to the blade $\mathrm{C}$ : $x_{\mathrm{C}}, y_{\mathrm{C}}, z_{\mathrm{C}}$. An explanation of this dependence is presented in Fig. 5, which shows an example of a crosssection of a blade. A tool that has a deformable layer is also shown. Depending on the curvature of the blade, the parameter $c$ is changed, which is a measure of the size of the contact surface: in the case of small internal curvatures, the parameter $c$ has a small value which increases with the increase of the curvature of the surface. In the case of external curvatures, the dependence is reversed. In the analyzed bibliography, such an approach to the problem was not encountered.
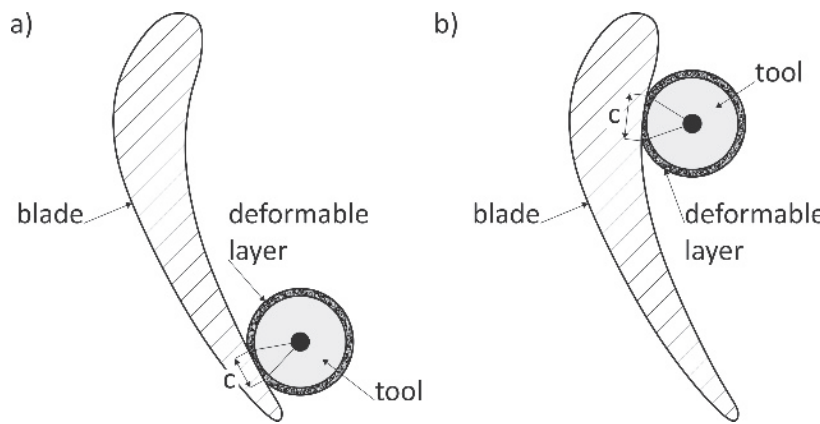

Figure 5 The size of the contact surface depending on the curvature at the point of contact of the tool with the blade: a) small internal curvature; b) large internal curvature

In the modeled process of blade grinding, fixed $v_{\mathrm{r}}$ and $v_{\mathrm{t}}$ parameters were assumed. Due to the fact that a very small layer of material is machined during the grinding process, the parameter $d$ related to the depth of cut and the influence of temperature $T$ are omitted. Simultaneously, the pressure forces are so small (several Newtons) that they do not cause significant deformations of the robot-grinder system and therefore the effect of the parameter $k$ related to the stiffness of the system is omitted. Factory procedures recommend changing the grinding tool every few dozen of blades made. With low grinding forces, the durability of the tool is very high, which guarantees a small tool degradation that allows omitting the $w$ factor associated with its wear. In addition, in the process of quality control of blades, the important parameters are geometrical dimensions, while the surface roughness $r$ is not assessed. Such far-reaching simplifications are acceptable because the blades are not cooperating with other solid objects, but they work in the vicinity of gases. In addition, the robotic process is to replace the previous manual work without changes regarding the conditions of product quality control. Therefore, the dependence of the grinding force on the most important variable parameters is presented as

$$
F_{\mathrm{n}}=f\left(Q, x_{\mathrm{C}}, y_{\mathrm{C}}, z_{\mathrm{C}}\right)
$$

To avoid the problem of analytical modeling of the complicated relationship between the desired force and the machining allowance $Q$ occurring at the point determined by the coordinates $x_{\mathrm{C}}, y_{\mathrm{C}}, z_{\mathrm{C}}$, with fixed process parameters $v_{\mathrm{r}}, v_{\mathrm{t}}$, the $\mathrm{NN}$ was used, which was learned dependence given by Eq. (2).

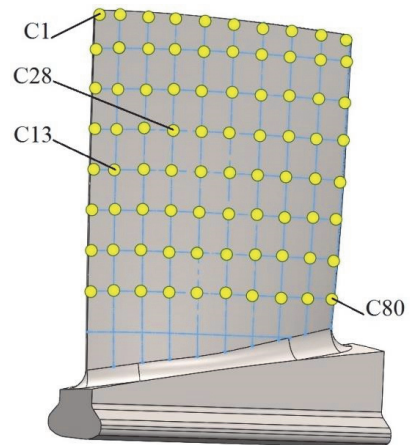

Figure 6 The area of the trailing surface of the blade with a grid of points applied 
The outer surface of the blade, called the trailing surface or the so-called ridge was covered with a regular grid of points located at distances not greater than the width of the machining tool (Fig. 6). For these points the value of the contact force was determined. A detailed description of the neural generator of the set contact force is given in section 3.3.

\section{ROBOTIZATION OF THE BLADE GRINDING PROCESS}

The designed robotic blade grinding station includes an IRB 140 robot manipulating the workpiece, a grinding tool and an IRB 1600 robot with a 3D scanning head installed. The measuring system works with ATOS Professional software and communicates with the IRC5 robot controller using the TCP/IP protocol. The RobotWare robot controller software provides control of two robots and is additionally equipped with a force control option. The variable process parameter - contact force - is determined by the $\mathrm{NN}$ on the basis of information from the measurement system.

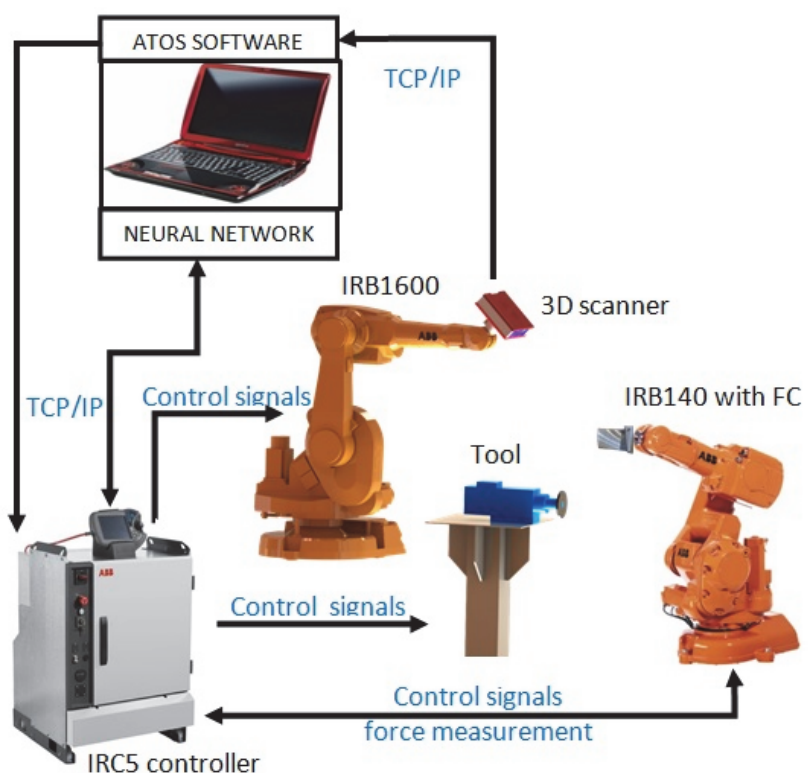

Figure 7 Diagram of the robotized workstation

The robotized workstation is shown schematically in Fig. 7.

\subsection{Robot with Force Control}

The conventional approach to material processing using a robot is based on the implementation of preprogrammed trajectories. In fact, there are a number of technological processes (casting, electrochemical treatment) that result in a semi-finished product with such a low accuracy that it is necessary to adapt the robot trajectory to the changing shape. One of the tools that makes this possible is the ForceControl application, in which the robot's movements are adapted to feedback from force sensors. In the solution proposed by the authors, the FC Pressure option was used. On the basis of a series of test works, a solution was proposed in which a fixed tool was used, and the object reference system (WorkObject) associated with the robot's arm was mobile. The robot's IRC5 software along with the set trajectories of motion were created in the RobotStudio program (Fig. 8). The use of the force control approach allows the trajectory to adapt to the variable shape of the workpiece.

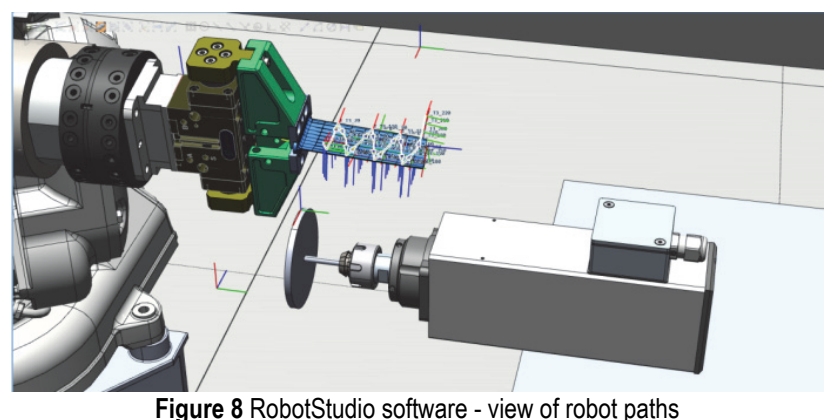

An advantage of the proposed approach is the reduction of the level of interference generated by the electro-spindle motor. When the rotating tool is on the robot arm, the force sensor registers the force value with interferences resulting from dynamic phenomena related to the movement of the tool [29].

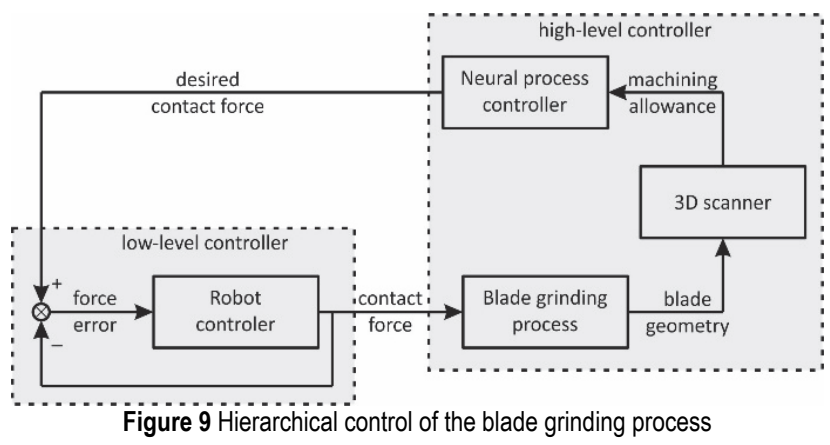

The hierarchical control structure shown in Fig. 9 was applied. The low-level controller uses a standard commercial solution based on the "FC pressure" strategy. The purpose of the controller is to realize the desired contact force while maintaining a constant feed rate. The desired contact force is generated by the high-level controller based on measuring machining allowances at selected points of the blade.

In the work, the quality of force control in the lowlevel was not analyzed, but the focus was on generating the desired contact force and the influence of the high-level controller on the quality of the grinding process.

\subsection{The System of Acquisition and Processing of Measurement Data}

An example of a blade before the grinding operation is shown in Fig. 10.

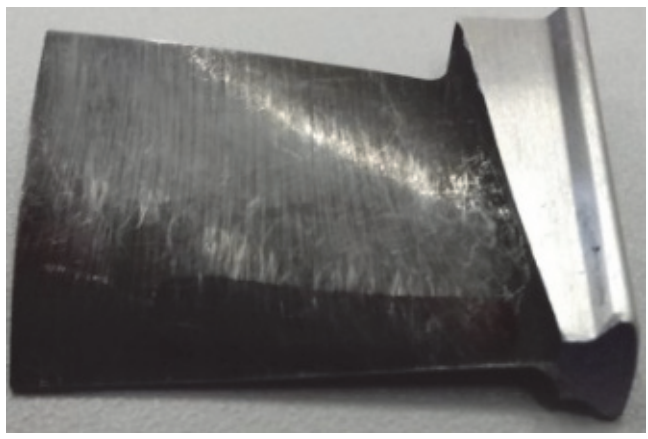

Figure 10 View of a blade before grinding 
The designed system allows the acquisition of measurement data containing information about the shape of a workpiece obtained as a result of 3D scanning (Fig. 2). After comparison with the standard CAD model, the values of machining allowances are determined at individual points of the blade (Fig. 11).

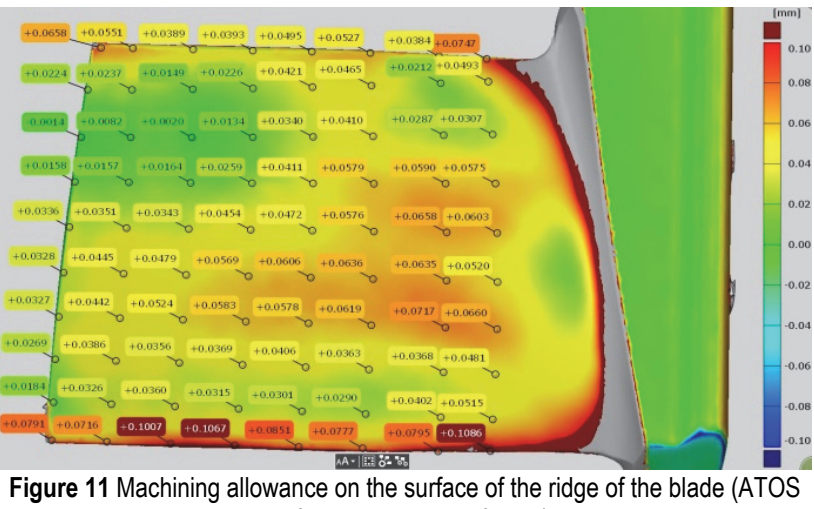
Professional Blade software)

Then, the obtained dimensions are automatically exported in the form of a text file to the robot's management system. In the process of determining machining allowances, the software add-on of the ATOS Professional Blade software dedicated to the inspection of all types of blades is used.

\subsection{Neural Process Controller}

The NN was learned dependence (2) with the following assumptions:

- tool rotation velocity is constant and amounts to $n_{\mathrm{t}}=4500 \mathrm{rpm}$,

- feed velocity, understood as the velocity of the blade relative to the tool, has a constant value when the blade is in contact with the tool and amounts to $v_{\mathrm{r}}=0.02 \mathrm{~m} / \mathrm{s}$

- blade returns, when the velocity is variable, are done without contact with the tool,

- the contact force may vary in the range of 2 to $8 \mathrm{~N}$ tool contact forces less than $2 \mathrm{~N}$ are not used, because there is no real possibility of controlling the force in the robot's control system; contact forces higher than 8 $\mathrm{N}$ cause the scorching of the blade surface, which is an unacceptable phenomenon.

In this way, the number of variable factors on which the desired contact force depends is reduced to two:

$$
F_{\mathrm{n}}=f(Q, n)
$$

where $Q$ - machining allowance, $n$ - number of the point specifying the area on the surface of the blade inserted instead of the coordinates $x_{\mathrm{C}}, y_{\mathrm{C}}, z_{\mathrm{C}}$.

The neural controller of the blade grinding process was built in the Matlab program, using the "Neural Network Toolbox" library. To approximate the dependence of the tool contact force on the machining allowance, a feedforward NN was selected and learned according to the backward error propagation algorithm [30]. For the purpose of the research work a software tool was developed to test the quality of $\mathrm{NN}$ approximation depending on the following parameters: number of hidden
NN layers, number of neurons in hidden layers, neuron activation functions, learning parameters, etc. The research was carried out by changing the number of hidden layers in the range 1-3 and the number of neurons in the layers in the range 3-30, and three types of neuron activation functions were tested: linear, sigmoidal unipolar and sigmoidal bipolar. Based on the results of these studies, a $\mathrm{NN}$ with two hidden layers with nine neurons in each of these layers was selected. In the hidden layers, sigmoidal unipolar functions of neuron activation were used, while linear activation functions were used in the output layer. The weights were learned according to an algorithm based on the Levenberg-Marquardt optimization method.

Data for learning the NN was obtained during measurement experiments. At 80 points located on the surface of the ridge of the blade, geometrical measurements were made to determine the size of the machining allowance (Fig. 10). Next, at the given contact force of the tool, the surface was machined and then the surface geometry was measured again. Thanks to this, the dependence of the thickness of the material layer collected on the tool contact force was determined experimentally. The values of contact force applied in successive experiments are successively $2,3,4,5,6,7,8 \mathrm{~N}$. The discussed experiments were carried out on 30 blades in order to take into account the variability of the blades in the set of measurement data. A breakdown of the measurement data obtained is shown in Tab. 1.

Table 1 Breakdown of the measurement data used to train the NN

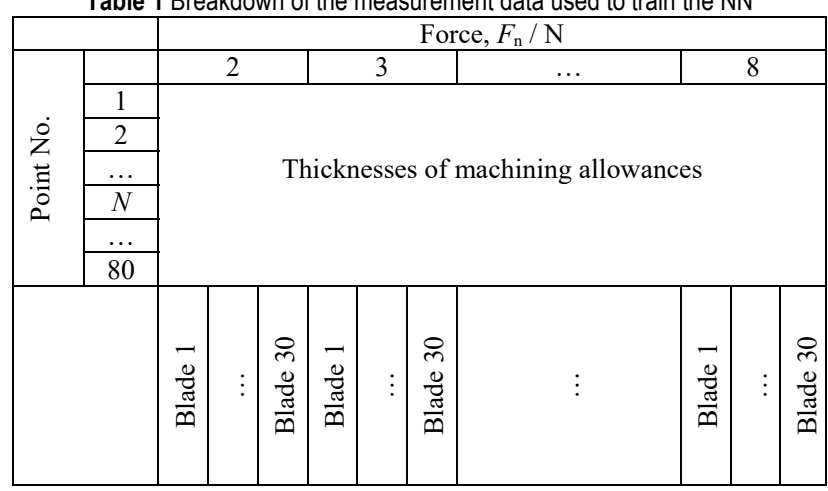

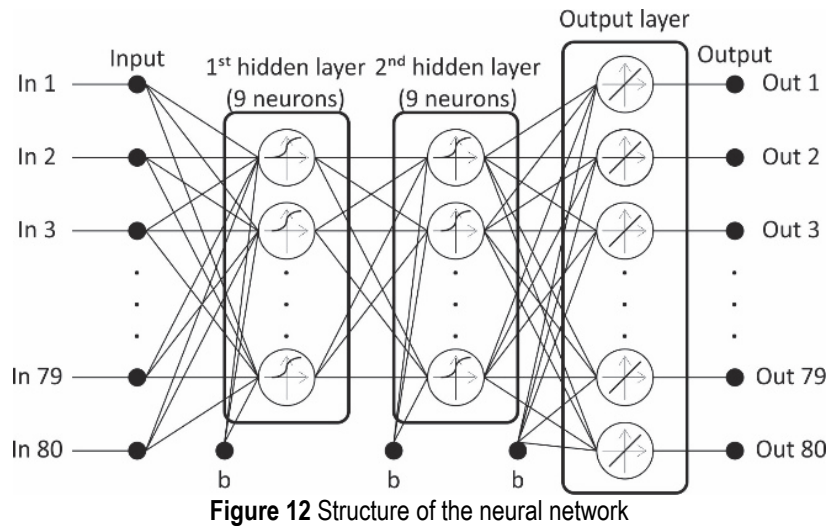

The NN was used to solve the inverse problem: for each of eighty measurement points, the neural process controller should generate the values of the tool contact forces, if the value of the machining allowance is known at these points. Information on the blade number was not taken into account in the process of learning the NN. The 
structure of the input and output layers of the $\mathrm{NN}$ results from the structure of the measurement data. The NN has 80 inputs and 80 outputs (Fig. 12), which is the number of measuring points. The input vector consists of the value of machining allowances at 80 measuring points. The input data is normalized to the interval [0-1]. The structure of the $\mathrm{NN}$ causes the value of the machining allowance at one point to affect the value of the generated force not only at this point, but also the values of contact forces at the remaining points. The advantage of such a solution is that between the generated points the generated contact force will not change drastically. From the point of view of smooth implementation of the machining process, this is of great importance. In addition, the process control system is less sensitive to the measurement errors.

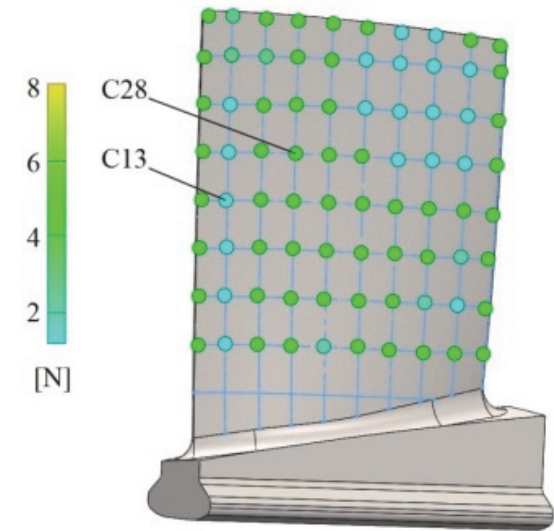

Figure 13 Graphical presentation of the values of the tool contact forces necessary to collect the machining allowance at individual measuring points

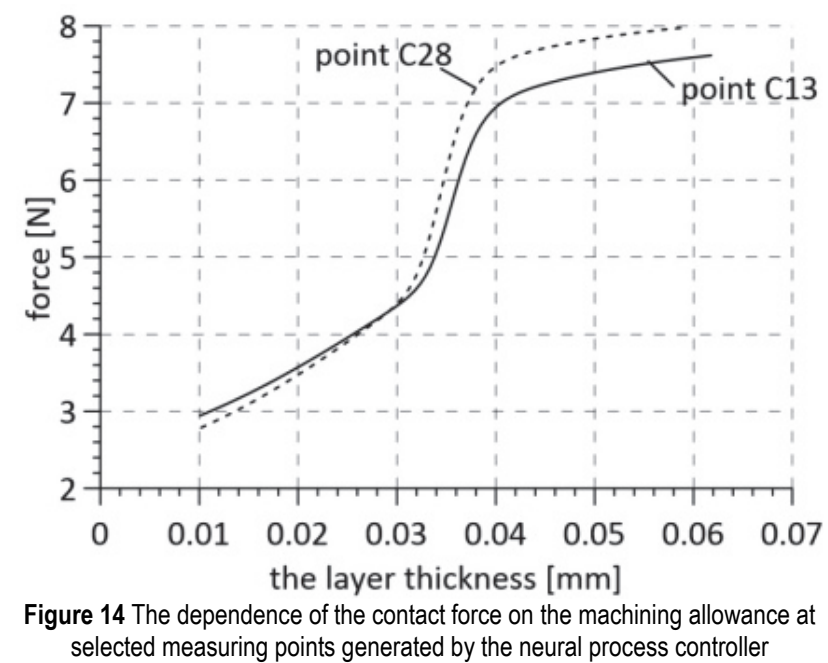

Fig. 13 graphically presents the values of contact forces at individual measuring points generated by the neural process controller for the blade shown in Fig. 10 and Fig. 11. At measurement points where a large machining allowance occurred, the generated contact force is greater than at points where the machining allowance was small. The exact relations between the tool contact force and the machining allowance at selected measuring points 13 and 28 are presented in Fig. 14. These are dependences obtained using a neural process controller. At other measuring points, these dependences have a similar character, although slightly different values.

\section{SOLUTION VERIFICATION}

The designed robotized workstation with neural process controller was subjected to verification tests. A block diagram of the robotic blade grinding process is shown in Fig. 15. The process starts with measuring the blade geometry and determining the machining allowance. Then, for each grid point, the contact force is determined, and the blade machining process begins. After the grinding process is carried out, the blade geometry measurement is performed again, and machining allowances are determined at individual points. If the machining allowances are within the specified tolerances, the process is terminated. Otherwise, the contact force is determined and the process of machining and checking the blade takes place until the desired geometry of the surface to be machined is obtained. A loop in the process is provided for inaccuracies of the control system or machining allowances that are too large to collect in one cycle. A view of the blade after grinding is shown in Fig. 16, and the measured allowances at the end of the process are shown in Fig. 17.

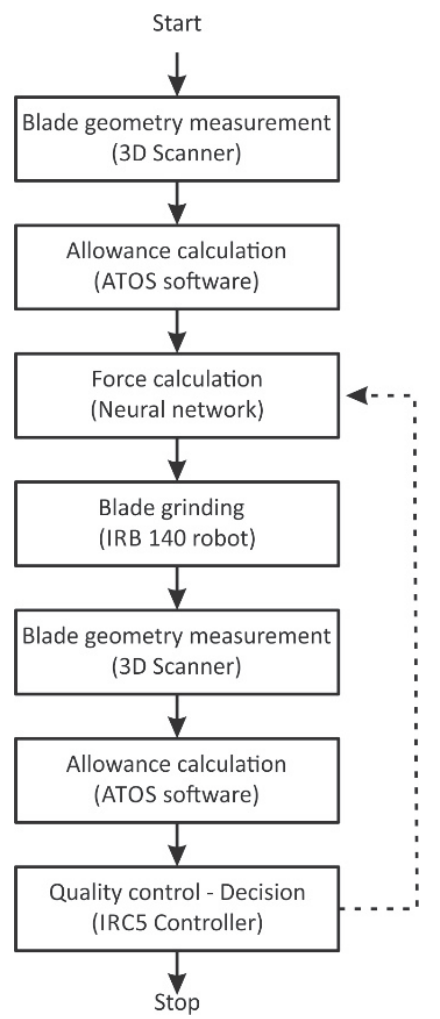

Figure 15 Block diagram of the blade grinding process

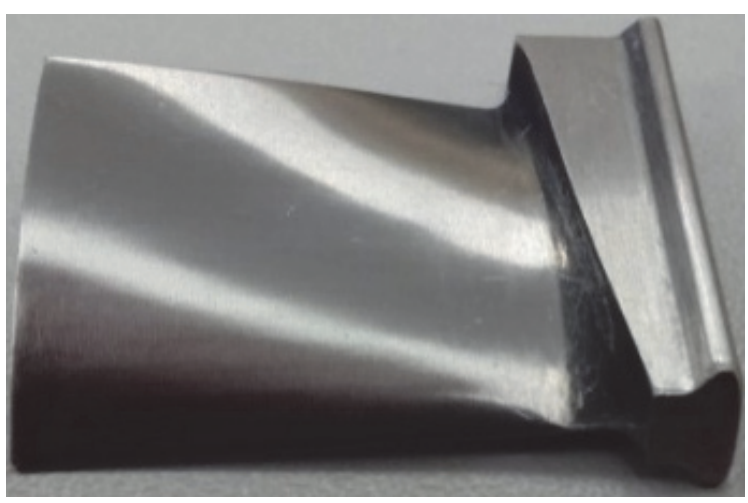

Figure 16 View of a blade after grinding 


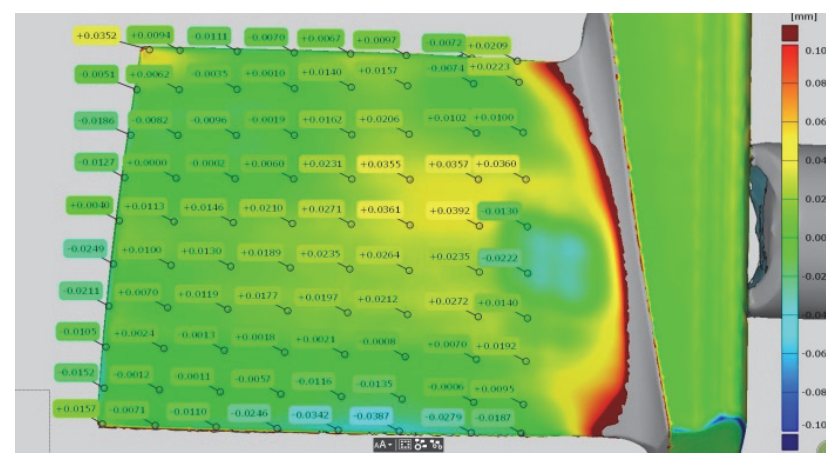

Figure 17 Measurement report after grinding

For the machined blade, the deviation from the desired shape should not exceed $\pm 0.05 \mathrm{~mm}$ at each measuring point. The presented results of experimental work show that the robotized grinding process of the blade ran correctly. For comparison, Fig. 18 shows the results of measuring the geometry of another blade, which was machined at a given constant grinding force at all points of the blade. This force was determined on the basis of the average allowance calculated on the basis of allowances at all measuring points of the blade.

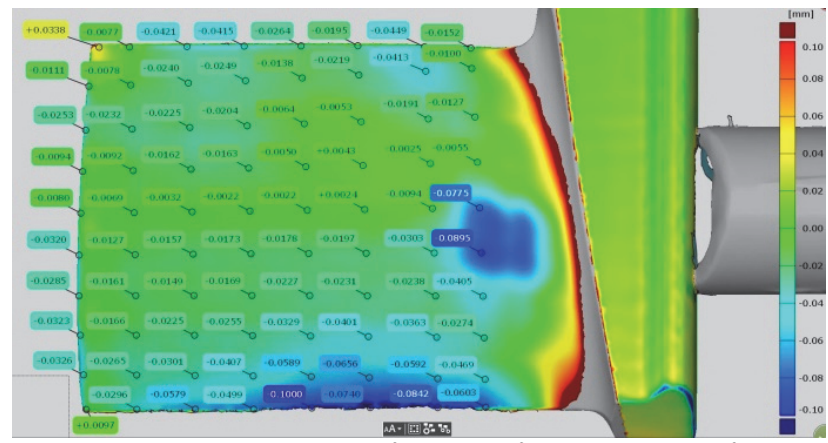

Figure 18 Measurement report after grinding for constant grinding force

It can be noticed that in this case there are areas on the surface of the blade in which the obtained dimensions do not fall within the given tolerance and the deviation is even $-0.1 \mathrm{~mm}$. This takes place in the areas with the smallest radii of curvature, which means that at a given grinding force there are the largest unit pressures, which cause removing more material than in areas with milder curvatures.

\section{CONCLUSION}

The approach presented in the work allows a blade to be machined in such a way as to adjust the contact force of the tool against a given surface fragment. This avoids a situation in which the contact force is constant over the entire surface, which would lead to too large losses or machining allowances of different areas of the surface.

In the research, a set of experimental data was used to determine the relationship between process parameters such as the position of the work area of the blade, the contact force and the thickness of the collected material layer. The novelty of the approach presented is precisely its consideration of the work area of the blade as a decision variable. It turned out that this affects the relationship between the strength of the contact force and the removed machining allowance. The use of the generalization properties of the NN learned on the experimental data set allowed the generation of information allowing the value of the blade-tool contact force to be assumed in such a way as to ensure the grinding process met the imposed requirements.

The presented solution is laboratory in nature and further work will be focused on automating the solution by integrating the $\mathrm{NN}$ in the robot controller, rather than on a separate computer. Further research will also concern the application of fuzzy systems in place of a neural network. This will allow the use of expert knowledge to solve the problem.

\section{REFERENCES}

[1] Li, Z., Jiang, Y., Guo, Q., Hu, C., \& Peng, Z. (2018). Multidimensional variational mode decomposition for bearingcrack detection in wind turbines with large driving-speed variations. Renewable Energy, 116, 55-73. https://doi.org/10.1016/.renene.2016.12.013

[2] Liu, F., Gao, S., Han, H., Tian, Z., \& Liu, P. (2019). Interference reduction of high-energy noise for modal parameter identification of offshore wind turbines based on iterative signal extraction. Ocean Engineering, 183, 372383. https://doi.org/10.1016/j.oceaneng.2019.05.009

[3] Li, Z., Goebel, K., \& Wu, D. (2019). Degradation modeling and remaining useful life prediction of aircraft engines using ensemble learning. Journal of Engineering for Gas Turbines and Power, 141(4), 041008. https://doi.org/10.1115/1.4041674

[4] Li, Z., Zhang, Z., Shi, J., \& Wu, D. (2019). Prediction of surface roughness in extrusion-based additive manufacturing with machine learning. Robotics and Computer-Integrated Manufacturing, 57, 488-495. https://doi.org/10.1016/.r.rim.2019.01.004

[5] Szybicki, D., Burghardt, A., Kurc, K., \& Pietruś, P. (2019). Calibration and verification of an original module measuring turbojet engine blades geometric parameters. Archive of Mechanical Engineering, 66, 97-109.

[6] Szybicki, D., Burghardt, A., Kurc, K., \& Gierlak, P. (2020). Device for Contact Measurement of Turbine Blade Geometry in Robotic Grinding Process. Sensors, 20(24), 7053. https://doi.org/10.3390/s20247053

[7] Huang, J., Ma, Z., Hu, Y., Wang, Y., \& Yu, S. (2008, December). Measurement of Aero-Engine BLISK Using Industry Robot. 2008 International Conference on Computer and Electrical Engineering, 130-134. https://doi.org/10.1109//CCEE.2008.45

[8] Fan-Jun, M., Xun, L., Zhi-Tong, C., \& Xiao-Wen, W. (2014). Study on the cantilever grinding process of aeroengine blade. Proceedings of the Institution of Mechanical Engineers, Part B: Journal of Engineering Manufacture, 228(11), 1393-1400. https://doi.org/10.1177/0954405414521190

[9] Sun, B. \& Li, B. (2015). Laser displacement sensor in the application of aero-engine blade measurement. IEEE Sensors Journal, 16(5), 1377-1384. https://doi.org/10.1109/JSEN.2015.2497363

[10] Li, W. L., Xie, H., Zhang, G., Yan, S. J., \& Yin, Z. P. (2016). 3 -D shape matching of a blade surface in robotic grinding applications. IEEE/ASME Transactions on Mechatronics, 21(5), 2294-2306. https://doi.org/10.1109/TMECH.2016.2574813

[11] Song, Y., Liang, W., \& Yang, Y. (2012). A method for grinding removal control of a robot belt grinding system. Journal of Intelligent Manufacturing, 23(5), 1903-1913. https://doi.org/10.1007/s10845-011-0508-6

[12] Kurc, K., Burghardt, A., Gierlak, P., \& Szybicki, D. (2018, September). Non-contact Robotic Measurement of Jet Engine Components with 3D Optical Scanner and UTT 
Method. International Workshop on Modeling Social Media, 151-164. https://doi.org/10.1007/978-3-030-11187-8_12

[13] Sun, Y., Giblin, D. J., \& Kazerounian, K. (2009). Accurate robotic belt grinding of workpieces with complex geometries using relative calibration techniques. Robotics and Computer-Integrated Manufacturing, 25(1), 204-210. https://doi.org/10.1016/j.rcim.2007.11.005

[14] Xu, X., Zhu, D., Zhang, H., Yan, S., \& Ding, H. (2017). TCP-based calibration in robot-assisted belt grinding of aero-engine blades using scanner measurements. The International Journal of Advanced Manufacturing Technology, 90(1-4), 635-647. https://doi.org/10.1007/s00170-016-9331-8

[15] Gierlak, P. (2019). Position/force control of manipulator in contact with flexible environment. acta mechanica et automatica, 13(1), 16-22. https://doi.org/10.2478/ama-2019-0003

[16] Duan, J., Zhang, Y., \& Shi, Y. (2016). Belt grinding process with force control system for blade of aero-engine. Proceedings of the Institution of Mechanical Engineers, Part B: Journal of Engineering Manufacture, 230(5), 858-869. https://doi.org/10.1177/0954405414563420

[17] Tahvilian, A. M., Liu, Z., Champliaud, H., \& Hazel, B. (2013). Experimental and finite element analysis of temperature and energy partition to the workpiece while grinding with a flexible robot. Journal of Materials Processing Technology, 213(12), 2292-2303. https://doi.org/10.1016/j.jmatprotec.2013.07.002

[18] Ren, X., Kuhlenkötter, B., \& Müller, H. (2006). Simulation and verification of belt grinding with industrial robots. International journal of machine tools and manufacture, 46(7-8), 708-716. https://doi.org/10.1016/j.jimachtools.2005.07.033

[19] Wang, J., Xu, J., Wang, X., Zhang, X., Song, X., \& Chen, X. (2019). A comprehensive study on surface integrity of nickel-based superalloy Inconel 718 under robotic belt grinding. Materials and Manufacturing Processes, 34(1), 61-69. https://doi.org/10.1080/10426914.2018.1512137

[20] Guo, M., Li, B., Ding, Z., \& Liang, S. Y. (2016). Empirical modeling of dynamic grinding force based on process analysis. The International Journal of Advanced Manufacturing Technology, 86(9-12), 3395-3405. https://doi.org/10.1007/s00170-016-8465-z

[21] Aurich, J. C., Biermann, D., Blum, H., Brecher, C., Carstensen, C., Denkena, B., Weinert, K. et al. (2009). Modelling and simulation of process: machine interaction in grinding. Production Engineering, 3(1), 111-120. https://doi.org/10.1007/s11740-008-0137-x

[22] Stępień, P. (2009). A probabilistic model of the grinding process. Applied Mathematical Modelling, 33(10), 38633884. https://doi.org/10.1016/j.apm.2009.01.005

[23] Jiang, J., Ge, P., Sun, S., Wang, D., Wang, Y., \& Yang, Y. (2016). From the microscopic interaction mechanism to the grinding temperature field: an integrated modelling on the grinding process. International Journal of Machine Tools and Manufacture, 110, 27-42. https://doi.org/10.1016/j.jimachtools.2016.08.004

[24] Lipiński, D. \& Bałasz, B. (2018). Modelling of surface roughness and grinding forces using artificial neural networks with assessment of the ability to data generalisation. The International Journal of Advanced Manufacturing Technology, 94(1-4), 1335-1347. https://doi.org/10.1007/s00170-017-0949-y

[25] Govindhasamy, J. J., McLoone, S. F., Irwin, G. W., French, J. J., \& Doyle, R. P. (2005). Neural modelling, control and optimisation of an industrial grinding process. Control Engineering Practice, 13(10), 1243-1258. https://doi.org/10.1016/j.conengprac.2004.11.006

[26] Latifinavid, M. \& Ilhan Konukseven, E. (2017). Hybrid model based on energy and experimental methods for parallel hexapod-robotic light abrasive grinding operations. The International Journal of Advanced Manufacturing Technology, 93(9-12), 3873-3887. https://doi.org/10.1007/s00170-017-0798-8

[27] Pandiyan, V., Caesarendra, W., Tjahjowidodo, T., \& Praveen, G. (2017). Predictive modelling and analysis of process parameters on material removal characteristics in abrasive belt grinding process. Applied Sciences, 7(4), 363. https://doi.org/10.3390/app7040363

[28] Wang, W., Liu, F., Liu, Z., \& Yun, C. (2017). Prediction of depth of cut for robotic belt grinding. The International Journal of Advanced Manufacturing Technology, 91(1-4), 699-708. https://doi.org/10.1007/s00170-016-9729-3

[29] Gierlak, P., Burghardt, A., Szybicki, D., \& Kurc, K. (2018, September). Eliminating the Inertial Forces Effects on the Measurement of Robot Interaction Force. International Workshop on Modeling Social Media, 67-76. https://doi.org/10.1007/978-3-030-11187-8_6

[30] Hagan, M. T., Demuth, H. B., \& Beale, M. H. (1996). Neural network design, PWS Pub. Co., Boston, 3632.

Contact information:

Andrzej BURGHARDT, Prof

Rzeszow University of Technology,

Faculty of Mechanical Engineering and Aeronautics,

Department of Applied Mechanics and Robotics,

al. Powstańców Warszawy 12, 35-959 Rzeszów, Poland

E-mail:andrzejb@prz.edu.pl

Dariusz SZYBICKI, PhD

Rzeszow University of Technology,

Faculty of Mechanical Engineering and Aeronautics,

Department of Applied Mechanics and Robotics,

al. Powstańców Warszawy 12, 35-959 Rzeszów, Poland

E-mail: dszybicki@prz.edu.p

Piotr GIERLAK, Prof.

(Corresponding author)

Rzeszow University of Technology,

Faculty of Mechanical Engineering and Aeronautics

Department of Applied Mechanics and Robotics,

al. Powstańców Warszawy 12, 35-959 Rzeszów, Poland

E-mail: pgierlak@prz.edu.pl

Krzysztof KURC, Prof.

Rzeszow University of Technology,

Faculty of Mechanical Engineering and Aeronautics,

Department of Applied Mechanics and Robotics,

al. Powstańców Warszawy 12, 35-959 Rzeszów, Poland

E-mail: kkurc@prz.edu.pl

\section{Magdalena MUSZYŃSKA, PhD}

Rzeszow University of Technology,

Faculty of Mechanical Engineering and Aeronautics,

Department of Applied Mechanics and Robotics,

al. Powstańców Warszawy 12, 35-959 Rzeszów, Poland

E-mail: magdaw@prz.edu.pl 